INT’L. J. AGING AND HUMAN DEVELOPMENT, Vol. 74(2) 143-161, 2012

\title{
THE ASSOCIATION BETWEEN ROUTINIZATION AND COGNITIVE RESOURCES IN LATER LIFE
}

\author{
ISABELLE TOURNIER \\ STÉPHANIE MATHEY \\ VIRGINIE POSTAL
}

Université Bordeaux Segalen

\begin{abstract}
The aim of this study was to investigate the association between routinization of daily life activities and cognitive resources during aging. Routinization could increase excessively during aging and become maladaptative in reducing individual resources. Fifty-two young participants $(M=20.8$ years) and 62 older participants $(M=66.9$ years) underwent a routinization scale and cognitive tasks of working memory, speed of processing, and attention. Results revealed that older adults presented a decrease on the three cognitive measures but no change on the routinization score. While no association was observed between routinization and cognitive measures for the young adults, a high routinization was associated with lower cognitive flexibility in the older adults. These findings are interpreted in the light of theories about the positive impact of variety in daily life environment on cognitive functions.
\end{abstract}

\section{INTRODUCTION}

Many studies have investigated the impact of environmental complexity on cognitive aging in recent years. Several results have suggested that complex leisure time activities have a positive impact on intellectual functioning in old and very old adults (Kliegel, Zimprich, \& Rott, 2004; Newson \& Kemps, 2005;

(c) 2012, Baywood Publishing Co., Inc. doi: http://dx.doi.org/10.2190/AG.74.2.c http://baywood.com 
Schooler \& Mulatu, 2001). An associated assumption is that a complex environment proposes a challenge that helps to maintain cognitive functioning (Schaie, 1984; Schooler \& Mulatu, 2001). Moreover, the complexity and variety of the environment could support learning strategies and cognitive mechanisms that are associated with the execution of cognitive tasks (Hultsch, Hertzog, Small, \& Dixon, 1999; Schaie, 1984). Hultsch et al. (1999) observed that engagement in activities requiring the processing of new information in the elderly was associated with less cognitive decline. In a recent study investigating the impact of a 10-12 week intervention concerning activities in elderly people (Tranter \& Koutstaal, 2008), participants were encouraged to engage in novel stimulating activities that involved creativity and problem-solving during group-sessions in the laboratory and "at home." The participants had better cognitive performances on fluid intelligence tests than the control group. Consequently, new engagement in intellectually stimulating activities may improve cognitive efficiency. Furthermore, it has been shown that the activities associated with a lower risk of developing Alzheimer's disease are not intellectual activities per se, but those that require complex cognitive processes required by the processing of novelty, such as planning or initiative-taking (Fabrigoule, Letenneur, Dartigues, \& Zarrouk, 1995). These findings support the assumption of a strong influence of the life environment on the aging of cognition and emphasize the need to consider the novelty component of activities and not only the quantity of practice. The novelty of activities seems an important factor regarding the positive effect of highly intellectual activities on cognition, because "the novelty of the context and the ill-defined and nonroutine nature of the challenges encountered require the individual to make choices with respect to selecting, prioritizing, and structuring problems, as well as organizing resources to develop solutions" (Stine-Morrow, 2007, p. 298).

\section{Routinization and Aging}

Given that performing novel intellectually stimulating activities seems particularly beneficial to aging, an important point is to consider the factors influencing engagement in different activities in aging. Thus, the novelty and variability of daily life activities could be reduced by excessive routinization. According to Bouisson (2002), routinization corresponds to the execution of behaviors or activities in the same rhythm or way over time, and seems to increase with aging. Routinization could be a way to cope by protecting the elderly from the difficulties and stress associated with novel situations. Surprisingly, while a growing number of studies focus on the factors which contribute to the intellectual stimulation, routinization per se, and notably during aging, has received little attention. In 1991, Reich and Zautra created a scale to access a psychological trait of routinization that motivated order and regularity in daily events in elderly adults. In comparison, the approach by Bouisson and colleagues 
(Bouisson, 2002; Bouisson \& Swendsen, 2003; see also, Bergua, Fabrigoule, Barberger-Gateau, Dartigues, Swendsen, \& Bouisson, 2006) can be distinguished by a focus on behaviors and activities, excluding personality dimensions. The specificity of this approach was to consider routinization as an adaptive response rather than a personality-determined response. Routines are commonly associated with habits and rigid behaviors. Thus, routines and habits may seem very similar. According to Betsch, Fiedler, and Brinkmann (1998), a routine is "a behavioral option that comes to mind as a solution when the decision-maker is confronted with a certain decision problem" (p. 862), while a habit is considered as a special case of routine, given that routines do not necessarily require a personal or repetitive experience of the behaviors Routines and habits are necessary to good adaptation, and the absence of habits requires controlled choices and behaviors (Verplanken, 2006). A major characteristic of habits is that their occurrence is automatized, so they can easily occur in parallel with other behaviors (Aarts \& Dijksterhuis, 2000). Diary studies of young adults by Wood, Quinn, and Kashy (2002) showed that habitual behaviors, unlike non-habitual behaviors, were associated with fewer thoughts concerning them and less intense emotion. The authors underlined the positive impact of habits on stress and feeling of control, in addition to cognitive economy and efficiency. Despite these positive effects, routinization could become non-adaptive. The case of routines maintained despite objective conditions requiring change has been attributed to rigidity, which describes the inability to change habits or sets (Chown, 1959). This resistance to change could affect beliefs, attitudes, or personal habits, emphasizing the multidimensional nature of rigidity (Rokeach, 1960). Thus, it is possible to distinguish behavioral, attitudinal, and cognitive rigidity. Together with routinization, the personal need for structure is a personality variable that corresponds to the motivation to structure the world cognitively in simple or unambiguous ways. Ciarrochi, Said, and Deane (2005) investigated the links between rigidity and mental health with the Personal Need for Structure Scale (PNS) (Thompson, Naccarato, Parker, Moskowitz, \& Moskowitz, 2001). The authors studied separately the two components of rigidity accessed with this scale: desire for simple structure corresponds to preferences for a particular state (e.g., "I enjoy having a clear and structured mode of life") whereas intolerance of uncertainty corresponds more to a demand for an environment in a particular way (e.g., "I don't like situations that are uncertain"). The results revealed that the intolerance for uncertainty component was associated with poor mental health, especially high depression and high anxiety. On the contrary, the desire for a simple structure was associated with less hopelessness, suggesting that this component provides a feeling of control over the environment. A similar distinction has been proposed by Reich and Zautra (1991) about the trait of routinization in elderly adults. They apprehended routinization as the consequence of both personality trait and adjustment strategies, and they developed a 20 -item scale to measure routinization. Two dimensions were revealed by factor analysis. 
Interestingly, a high score on "having order and routine" was associated with less reporting of undesirable everyday events, whereas a high score on "disliking disruption" was associated with more undesirable everyday events. Both studies (Ciarrochi et al., 2005; Reich \& Zautra, 1991) highlighted the possible transition from beneficial to harmful routinization. Bouisson (2002) suggested that adaptive routinization could become maladaptive when routines are so important that behaviors become inflexible and resistant to change. A possible consequence of excessive routinization could be a drastic decrease in environmental variety, leading to reduced capacity to adapt to novelty and to an increase of rigidity.

The fact that habits and rigidity increase with aging is a popular assumption (Vollhardt, 1990). However, few studies have directly compared the routinization between young and older adults. To our knowledge, the age effect on routinization has been studied mostly in populations over 60 years. Such studies examining the evolution of scores of routinization preferences in adults over 60 years have shown greater routinization in the older participants (Bouisson, 2002; Bouisson \& Swendsen, 2003; Zisberg, Zysberg, Young, \& Schepp, 2009; but see Bergua et al., 2006). Nevertheless, a comparison between young adults $(M=20.7$ years) and older adults ( $M=68.5$ years) did not reveal any increase of routinization with aging (Tournier \& Postal, 2010). The discrepancy between these data could be partly explained by differences between the characteristics of participants (i.e., institutionalized or not, old age vs. very old age, presence or not of a younger group). We note that some concepts similar to the concept of routinization seem to be influenced by aging. A review of the literature points to an increase in rigidity of thought and behavior, notably after 60 years (Schultz \& Searleman, 2002; but see Vollhardt, 1990). Concerning electrophysiological measures of cerebral activity, recent studies showed a decrease in the processing of new targets by elderly associated with a decline in the P3 amplitude during event-related potentials (Daffner, Ryan, Williams, Budson, Rentz, Wolk, et al., 2006). Furthermore, the processing of new targets was related with cognitive status: young and older adults with high cognitive performances spent more time viewing novel targets than participants with average cognitive performance (Daffner, Chong, Riis, Wolk, Holcomb, Budson, et al., 2007). The results showed that the influence of cognitive performance was higher in older participants, suggesting that the association between cognitive status and engagement by novelty gets stronger with aging.

\section{Cognitive Resources and Routinization during Aging}

Routinization and cognitive resources seem closely associated. On the one hand, routines could allow cognitive economy and, on the other hand, cognitive status seems associated with perception of novelty. Moreover, the decrease in environmental variety associated with excessive routinization could reduce 
cognitive resources. In the domain of cognitive aging, the theory of processing resources posits that the negative age effect on some cognitive tasks could be due to changes with age in basic information-processing capacities (Park, Smith, Lautenschlager, Earles, Frieske, Zwahr, et al., 1996; Salthouse, 1991). The most frequently quoted resources in the literature are working memory, speed of processing, and attention (Levitt, Fugelsang, \& Crossley, 2006; Salthouse, Kausler, \& Saults, 1988). First, according to Baddeley (1986), working memory is a limited capacity system for maintaining and manipulating information. Previous research showed a decline in working memory with aging (Emery, Hale, \& Myerson, 2008; Hertzog, Dixon, Hultsch, \& MacDonald, 2003; Salthouse, 1994a)). Second, according to the processing speed theory (Salthouse, 1996), the decrease with aging in the execution speed of cognitive operation could explain age differences in many aspects of cognitive functioning. Thus, cognitive operations could be executed too slowly to be successful in a limited time, and this slowing could reduce the capacity to process information simultaneously. Many studies suggested a decline in processing speed with aging (Finkel, Reynolds, McArdle, \& Pedersen, 2007; Lemke \& Zimprich, 2005; Levitt et al., 2006). Third, attention is another important resource in which selective and divided attention are the two main aspects. Selective attention is the ability to focus on relevant information while ignoring irrelevant information, whereas divided attention corresponds to the ability to process information from different locations or to switch between tasks (Kramer \& Madden, 2008). Previous studies suggested negative changes in selective attention and divided attention during aging (Hommel, Li, \& Li, 2004; Kray, Li, \& Lindenbergber, 2002; Verhaeghen \& De Meersman, 1998).

Much information is shared by the environment in daily life, and the use of cognitive structures is a way to reduce cognitive resources involved in the understanding and processing of these elements (Neuberg \& Newsom, 1993). Stine-Morrow (2007) suggested that the choice in how effort is allocated may be an important determinant of cognitive change over the life span both directly (i.e., via attentional engagement) and indirectly (i.e., engagement sculpts neural substrates linked to component abilities). For example, routinization might have an impact on the allocation of cognitive resources. As previously noted, routinization could be a way to cope with poor cognitive resources. The increase in the use of external and internal strategies could be a way to compensate the memory reduction occurring with aging (Zacks, Hasher, \& Li, 2000). According to metamemory estimations, young and older adults with high routinization use more external strategies than adults with lower routinization, while older adults with high routinization also report using more internal strategies than older adults with lower routinization (Tournier \& Postal, 2010). This increase in strategy use with routinization could be an attempt to deal with memory loss. Although Bergua et al. (2006) did not observe any direct association in elderly adults between routinization and the Mini Mental State Examination (MMSE) (Folstein, Folstein, 
\& McHugh, 1975), a measure of cognitive status, they obtained a significant association between routinization and lower MMSE scores at two evaluations 3 years apart. A global measure of the cognitive status of six items (OrientationMemory-Concentration test; Wade \& Vergis, 1999) has also been used by Zisberg et al. (2009). They failed to observe any association between this test and the routinization scale of Reich and Zautra (1991) in old adults. The absence of direct links between routinization and cognition could be explained by the lack of specificity of the cognitive measures used. In using more complex and specific cognitive tasks, Hess (2001) investigated links between scores on the personality measure of the PNS and cognitive resources in adults between 21 and 85 years. Hess argued that older adults could choose to simplify their interactions with the environment by limiting the complexity and quantity of information to be processed, and consequently developing the use of routinized behaviors. Hierarchical regression analyses revealed that higher scores on the PNS were associated with fewer available resources (i.e., addition of measures of vocabulary, working memory, and speed of processing). Interestingly, the results did not show any direct relationship between age and need for structure score, but there was an indirect one given that age was associated with fewer cognitive resources. Finally, the author emphasized the need not only to consider available resources or capacities but also to apprehend the factors influencing their use.

\section{The Issue}

Previous studies have suggested that nonroutine activities could have positive effects on cognition during aging. On the other side, it seems possible to hypothesize that preference for routine is associated with a decline of cognitive resources. Thus, the aim of the present study was to investigate the effect of age on routinization by comparing young and older adults. We also investigated a possible interaction between age and routinization on cognitive resources. Indeed, as previous studies failed to observe any direct links between routinization and cognition with a general measure of cognition (e.g., MMSE), we decided to use more specific measures of cognitive abilities. To do so, in accordance with the theory of the decrease in processing resources during aging, we measured working memory, speed of processing and attention. First, we hypothesized that older adults would have higher routinization and fewer cognitive resources than young adults. Second, we hypothesized that young and older adults with higher routinization would present fewer cognitive resources than their pairs with lower routinization. Finally, we made the assumption that the effect of routinization on cognitive resources would be greater for older than young adults. 
ROUTINIZATION AND COGNITIVE AGING / 149

METHOD

\section{Participants}

\section{Main Characteristics}

Fifty-two young (range 18-26 years, $M=20.8, S D=2.2$ ) and 62 older (range 60-87 years, $M=66.9, S D=6.6$ ) French-speaking participants took part in this study. All were volunteers and were recruited during university lessons. Young adults were students in human sciences at Bordeaux Segalen University, and older adults were students in the University for Senior Citizens in Bordeaux. To avoid including elderly participants with dementia, we selected only subjects with a Mini Mental State Examination (MMSE) (Folstein et al., 1975) score of 27 or more $(M=28.92, S D=0.90)$. The number of education years was equivalent for young $(M=13.91, S D=2.06)$ and older adults $(M=14.26, S D=2.82), t(112)=$ $-0.52, p>.10$. The level of vocabulary measured by part B of the Mill-Hill test (Deltour, 1998) was greater in the older group $(M=40.69, S D=2.10$ vs. $M=37.22, S D=2.44), t(112)=-7.91, p<.001$. The young and older groups were composed of $75 \%$ and $68 \%$ women respectively, $\chi^{2}=0.72, p>.10$ (see Table 1 ).

\section{Routinization Groups}

To address the question of the relation between routinization and cognitive resources during aging, we screened participants according to routinization scores. To do so, we used the Preferences for Routinization Scale (EPR) (Bouisson, 2002) which is composed of 10 items in the French language. This 5-point Likert scale accesses daily life habits and behaviors (e.g., sleep and meal schedules, organization of personal objects, social exchange) with items

Table 1. Participants' Characteristics According to Age and Routinization Group $(n=114)$

\begin{tabular}{lcccccc}
\hline & \multicolumn{2}{c}{ Young adults } & & \multicolumn{2}{c}{ Older adults } \\
\cline { 2 - 3 } \cline { 6 - 7 } Characteristic & LR & HR & & LR & HR \\
\hline Number & 31 & 21 & & 28 & 34 \\
Age & $21.1(2.5)$ & $20.4(2.0)$ & & $66.2(6.4)$ & $67.6(6.9)$ \\
Study (years) & $14.3(2.2)$ & $13.5(1.8)$ & & $14.6(3.0)$ & $13.9(2.7)$ \\
Mill-Hill (/44) & $37.7(2.4)$ & $36.8(2.5)$ & & $40.5(2.4)$ & $40.9(1.9)$ \\
MMSE (/30) & - & & & 29 & $(0.9)$ & $28.9(0.8)$ \\
\hline
\end{tabular}

Note: $L R=$ lower routinization, $\mathrm{HR}=$ higher routinization. 
such as "I like to move and to change activities" or "I prefer to get up and to go to bed at the same time every day." The degree of agreement with different sentences is rated and the total score is from 10 to 50 , higher scores representing greater preferences for routinization. The internal consistency is acceptable $(\alpha=0.73)$, the test-retest reliability is good $(r=0.84)$, and the predictive validity of actual behavioral routinization is strong (Bouisson, 2002; Bouisson \& Swendsen, 2003). The participants were distributed in two routinization levels according to their routinization scores. The characteristics of the participants in the age and routinization groups are presented in Table 1. Given that the median score was 24 for the young adults and 26 for the older adults, 25 was used as a common cutoff in order to have the same criteria for young and older adults. Participants with a score of 24 and less were considered as lower routinized and participants with a score of 25 and more were considered as higher routinized.

For the young adults, the lower routinization group was composed of 31 participants and their mean EPR score was $20.8(S D=2.4)$. The higher routinization group was composed of 21 participants and the mean score to EPR was 28.1 $(S D=2.8)$. $T$-test confirmed that the routinization score was significantly different between the two groups, $t(50)=-9.99, p<.001$. For the older adults, the lower routinization group was composed of 28 participants and their mean EPR score was $19.7(S D=2.8)$. The higher routinization group was composed of 34 participants and their mean EPR score was $28.5(S D=2.5)$. The routinization score was significantly different between the two groups, $t(60)=-13.25, p<.001$. Additional $t$-tests have been run to investigate possible difference of age, study, and vocabulary between lower and higher routinization groups of young and older adults. Concerning young adults, lower and higher routinization groups were not different on age, $t(50)=1.23, p>.10$, years of study, $t(50)=1.31, p>.10$, and Mill-Hill score, $t(50)=1.32, p>.10$. In the same way, for older adults, lower and higher routinization groups were not different on age, $t(60)=-0.82, p>.10$, years of study, $t(60)=0.96, p>.10$, and Mill-Hill score, $t(60)=-0.70, p>.10$.

\section{Materials}

\section{Operation Span Task}

In order to measure working memory, we used a modified and computerized version of the Operation Span Task (Turner \& Engle, 1989). A mathematical operation and a to-be-remembered word were presented on a computer screen (e.g., " $2 \times 5+7=19$ Boat"). First, the participant had to say aloud if the operation was true or not, and then he had to say aloud the written word. The next operation-word pair was presented as soon as the participant read the word (Emery et al., 2008). Presentation of the pairs was controlled by the experimenter in order to prevent differences in use of strategies by participants. At the end of each list, the cue "Recall" was presented and participants recalled the words of the current trial. The task was composed of 15 trials with between two to six 
operation-word pairs, with three trials for each length. Trials were presented in increasing length and the task was finished after three consecutive errors. Three supplementary trials were used for practice (respective lengths of two, three, and four items). We verified that participants correctly achieved at least $80 \%$ of the mathematical operations, in order to be sure that they were paying attention to the process. As dependant variable, we measured span size.

\section{The Boxes Task}

In order to measure processing speed, we used a computerized adaptation of the Boxes task (Salthouse, 1994b). A series of 100 squares with a missing side were presented on the computer screen. Participants indicated the missing side by pushing a button on a computer keyboard, as quickly and precisely as possible. Buttons for responses were indicated in green and were arranged to form a square, in order to avoid difficulties in memorizing responses keys. A series of 20 squares was given for practice. The mean response time in milliseconds for correct responses was scored.

\section{TMT}

The TMT (Reitan, 1958) is composed of two parts: part A involves connecting circles with numbers (i.e., 1-2-3-...-24-25) whereas part B requires alternately connecting circles with numbers and circles with letters (i.e., 1-A-2-B-....-L-13). Circles were presented in a pseudo-random order on an A4 page and participants were instructed to complete the task as quickly as possible and without mistakes. In case of mistakes, the instructions stipulated to return to the previous point and to continue the task. Given that TMT errors are very infrequent in healthy older adults (Amieva, Lafont, Auriacombe, Rainville, Orgogozo, Dartigues, et al., 1998), we decided to study only response time. Consequently, we chose the TMT modality in which each mistake is indicated to the participant for immediate correction, in order to avoid any unnecessary loss of time associated with errors recognized too late. We measured responses times in seconds for part A and part B.

\section{RESULTS}

\section{Effect of Age on Routinization}

$T$-tests conducted to examine the effect of age on EPR scores showed that mean EPR scores were equivalent for young (24.5) and older adults (24.1), $t(112)=$ $-0.80, p>.10$. The mean EPR scores of the young and older adults did not differ significantly either in the low (20.8 vs. 19.7), $t(57)=1.72, p=.09$ or high routinization group (28.1 vs. 28.5), $t(53)=-.49, p>.10$. 


\section{Effect of Age and Routinization on Cognitive Resources}

We conducted a 2 (age group) $\times 2$ (routinization group) analysis of variance (ANOVA) on the operation span task and the boxes task. For the TMT, we conducted a 2 (age) $\times 2$ (routinization group) ANOVA with part A and part B in repeated measures. Mean scores and standard deviations are presented in Table 2. Analyses of covariance (ANCOVAs) were also conducted in order to control the influence of other cognitive resources on the cognitive resource as the dependent variable.

\section{Operation Span Task}

Older adults had lower scores than young adults (3.49 vs. 3.87), $F(1,110)=$ $4.20, p<.05$. The main effect of routinization was not reliable, with 3.79 for lower routinized adults and 3.57 for higher routinized adults, $F(1,110)=1.42, p>.10$. The interaction between age and routinization was not significant, $F(1,110)=$ $1.07, p>.10$.

The age effect became non-significant with the Boxes task entered as covariable, $F<1$. The age effect was also non-significant with TMT part A or B entered as covariable, respectively $F(1,109)=2.16$ and $F(1,109)=2.28, p>.10$.

\section{Boxes Task}

Older adults had slower response times than young adults ( $856 \mathrm{~ms}$ vs. $541 \mathrm{~ms}$ ), $F(1,110)=288.01, p<.001$. The main effect of routinization was not reliable, with $706 \mathrm{~ms}$ for lower routinized adults and $691 \mathrm{~ms}$ for higher routinized adults, $F<1$. The interaction effect between age and routinization was not significant, $F(1,110)=1.87, p>.10$.

Table 2. Mean Scores and Standard Deviation (in Parentheses) According to Age and Routinization

\begin{tabular}{|c|c|c|c|c|}
\hline \multirow[b]{2}{*}{ Test } & \multicolumn{2}{|c|}{ Young adults } & \multicolumn{2}{|c|}{ Older adults } \\
\hline & LR & $\mathrm{HR}$ & LR & $\mathrm{HR}$ \\
\hline Operation span (size) & $3.89(1.11)$ & $3.86(1.27)$ & $3.70(0.86)$ & $3.28(0.72)$ \\
\hline Boxes (ms) & $562 \quad(90)$ & $521 \quad(82)$ & 851 (113) & $861 \quad(88)$ \\
\hline Trail Making A (s) & $24.1 \quad(5.8)$ & 24.9 (4.9) & $36.6 \quad(9.8)$ & $41.8(10.8)$ \\
\hline Trail Making B (s) & $45.1(11.8)$ & $43.9 \quad(7.5)$ & $71.3(20.4)$ & $85.8(24.7)$ \\
\hline
\end{tabular}

Note: $L R=$ lower routinization, $\mathrm{HR}=$ higher routinization. 
The age effect remained significant when the operation span task and the TMT parts A and B were entered as covariables, respectively $F(1,109)=271.12$, $F(1,109)=126.65$ and $F(1,109)=120.32, p<.001$.

TMT

Older adults had slower response times than young adults (58.9 s vs. $34.5 \mathrm{~s}$ ), $F(1,110)=111.60, p<.001$. The main effect of routinization was also significant, with $49.1 \mathrm{~s}$ for higher routinized adults and $44.3 \mathrm{~s}$ for lower routinized adults, $F(1,110)=4.41, p<.05$. The effect of parts was significant, with $61.5 \mathrm{~s}$ for part $\mathrm{B}$ and $31.9 \mathrm{~s}$ for part $\mathrm{A}, F(1,110)=420.41, p<.001$. The interaction between age and routinization was significant, $F(1,110)=4.77, p<.05$, higher routinized older participants being longer to respond than lower routinized older participants $(63.8 \mathrm{~s}$ vs. $53.9 \mathrm{~s})$, which was not the case for the young adults ( $34.4 \mathrm{~s}$ vs. $34.6 \mathrm{~s})$. The interaction between age and parts was also significant, $F(1,110)=44.99$, $p<.001$, older adults having slower response times than young adults in part A $(39.6 \mathrm{~s}$ vs. $24.5 \mathrm{~s})$ and to a greater extent in part B $(78.9 \mathrm{~s}$ vs. $44.5 \mathrm{~s})$. The interaction between routinization and part was not significant, $F(1,110)=1.57, p>.10$. In Part A, response times were $30.3 \mathrm{~s}$ for lower routinized and $33.4 \mathrm{~s}$ for higher routinized participants. In part B, response times were $58.2 \mathrm{~s}$ for lower routinized and $64.8 \mathrm{~s}$ for higher routinized participants. Finally, the interaction between age, routinization, and part was significant, $F(1,110)=3.91, p=.05$. In older adults, QA: part A or B? higher routinized participants had slower response times than lower routinized participants, notably for part B ( $85.8 \mathrm{~s}$ vs. $71.3 \mathrm{~s})$ compared to part A ( $41.8 \mathrm{~s}$ vs. $36.6 \mathrm{~s})$. In young adults, higher and lower routinized participants had equivalent response times for part A ( $24.9 \mathrm{~s}$ vs. $24.1 \mathrm{~s})$ and part B (41.8 s vs. $36.6 \mathrm{~s})$.

In part $\mathrm{A}$, older adults had slower response times than young adults $(39.2 \mathrm{~s}$ vs. $24.5 \mathrm{~s}), F(1,110)=79.37, p<.001$. The effect of routinization failed to attain significance, with $33.4 \mathrm{~s}$ for higher routinized adults and $30.3 \mathrm{~s}$ for lower routinized, $F(1,110)=3.39, p=.07$. The interaction between age and routinization was not significant, $F(1,110)=1.75, p>.10$. The age effect remained significant with the operation span task entered as covariable, $F(1,109)=75.32, p<.001$, but did not achieve significance with the boxes task entered as covariable, $F(1,109)=$ $3.12, p=0.08$.

In part B, older adults had slower response times than young adults (78.6 $\mathrm{s}$ vs. $44.5 \mathrm{~s}), F(1,110)=95.85, p<.001$. The effect of routinization failed to attain significance, with $64.8 \mathrm{~s}$ for higher routinized adults and $58.1 \mathrm{~s}$ for lower routinized, $F(1,110)=3.66, p=.06$. The interaction between age and routinization was significant, $F(1,110)=5.15, p<.05$. Contrast analyses indicated that the responses times of higher and lower routinized young adults did not differ ( 43.9 s vs. $45.1 \mathrm{~s}$ ), $F<1$, whereas higher routinized older adults had slower response times than lower routinized ones $(85.8 \mathrm{~s}$ vs. $71.3 \mathrm{~s}), F(1,110)=$ $9.74, p<.01$. The age effect remained significant with the operation span task, 
$F(1,109)=91.59, p<.01$, and the boxes task entered as covariables, $F(1,109)=$ $9.60, p<.01$. The interaction between age and routinization also remained significant with the operation span task, $F(1,109)=5.07, p<.05$, and the boxes task entered as covariables, $F(1,109)=3.90, p=.05$.

\section{DISCUSSION}

Previous studies suggested a positive effect of environmental variety on cognitive aging. Complexity and novelty of stimuli could require cognitive mechanisms and learning strategies necessary for the execution of cognitive tasks (Schaie, 1984). However, other studies claimed that elderly adults become more routinized, preferring to perform activities and behaviors in the same order or way over time (Bouisson, 2002; Reich \& Zautra, 1991). Whereas the latter studies suggested links between routinization and cognitive abilities, others using a global cognitive measure did not show any clear association (Bergua et al., 2006; Zisberg et al., 2009). Consequently, the aim of this study was, first, to examine whether aging is associated with an increase of the routinization by comparing young and older adults and, second to investigated the association between routinization and cognition with more specific measures to assess processing resources.

An original aspect of our research was, in fact, to study the effect of aging on routinization by comparing young and older adults. Our data did not show any increase in routinization with age. Moreover, correlations within the older adults group did not show that routinization increased with aging $(r=0.06, p>.10)$, which is consistent with a previous finding by Bergua et al. (2006). The absence of age effect on routinization when comparing young and older adults also replicates recent findings from Tournier and Postal (2010). The discrepancy with other results (Bouisson, 2002; Zisberg et al., 2009) could be due to differences between populations studied. In the Bouisson study, $51 \%$ of the participants were from retirement homes, while all of the participants in the Zisberg et al. study were. Living in retirement homes is a factor associated with more dependency and could explain differences in routinization scores with age. In accordance with our results, Bergua et al. (2006) did not find an age effect on routinization when investigating a population of older adults of whom only $2.5 \%$ were institutionalized. Another possible explanation for the absence of age effect in our study could be the fact that the participants were volunteers who agreed to come to university to participate in a research project (Hess, 2001). Thus, our older adults could have lower routinization than the general elderly population. Finally, the relatively small number of participants per group (from 21 to 34) might not be large enough to observe significant differences in routinization score according to age or for working memory or processing speed according to routinization.

The most important finding of this study is the fact that divided attention was different according to routinization level only in older adults group. Indeed, 
although participants with higher routinization tended to be slower in part A and part B of the TMT than participants with lower routinization, the significant interaction between age and routinization in part B revealed that only older adults presented a negative effect in relation to routinization level. Given that previous studies showed that TMT involves psychomotor speed and visual search (e.g., Crowe, 1998), we therefore ran ANCOVAs in order to control for possible interrelations between cognitive measures. When the operation task was entered as a covariable, the age effect remained significant both in part A and B. When the boxes task was used as a covariable, the age effect became a trend on part A and remained significant on part $\mathrm{B}$. The interaction between age and routinization remained significant with the operation task or the boxes task as a covariable.

In accordance with previous studies on cognitive aging (e.g., Emery et al., 2008; Finkel et al., 2007; Salthouse, 1991; Tun, O'Kane, \& Wingfield, 2002), we found a negative age effect on performances of working memory, speed of processing, and attention. These results confirm the decrease in cognitive resources during aging (Park et al., 1996; Salthouse, 1991) and justify the use of analyses of covariance. We did not observe any effect of routinization or interaction between routinization and age on working memory and speed of processing. In this case, could the slowing of processing be responsible of the effect of the routinization observed on the TMT? Two results suggest that differences in processing speed are not the only explanation for the routinization effect during the TMT. First, the absence of routinization effect or interaction between age and routinization for the measure of speed of processing (i.e., boxes task) shows that the most routinized participants did not have longer response times. Second, the significant interaction between age and routinization for older adults on the TMT persisted after controlling speed of processing. In addition, the difference on the TMT between lower and higher routinized older adults could not be due to age, vocabulary, or years of education, given that these variables were not statistically different between the groups.

Interestingly, our results show that the only cognitive ability related to routinization was divided attention, which involves flexibility. For example, in the TMT, flexibility is necessary to alternate successfully between letters and numbers (Crowe, 1998). At first sight, and concordant with the multidimensional nature of rigidity proposed by Rokeach (1960), this association suggests a common factor explaining the association between behavioral rigidity (i.e., routinization) and cognitive rigidity (i.e., lack of flexibility). In other words, high behavioral rigidity could be associated with high cognitive rigidity in the same individual. However, our results are not in favor of this interpretation, because only older adults showed high routinization accompanied with a lack of flexibility. A possible explanation why only older adults presented an association between routinization and flexibility could be that the repetition of routinized behaviors during one's life causes a decrease in flexibility. Thus, this decrease in a cognitive resource could be explained by theories postulating that a complex life 
environment offers challenges contributing to maintenance of cognitive functioning (Schaie, 1984). Thus, excessive routinization could reduce the diversity of stimuli to be processed and the need to perform complex reasoning. This lack of complexity could involve disuse of learning strategies and cognitive mechanisms necessary for the execution of complex tasks (Hultsch et al., 1999) and, in turn, increase routinization. The fact that routinized actions or activities involve habitual scripts and automatic responses that reduce the requirement for flexibility could explain the selective effect of routinization on flexibility in our results. We could take the example of a ride in a car: an unknown route requires flexibility to drive precisely while supervising constraints associated with driving (e.g., other vehicles, pedestrians, or traffic lights) and simultaneously looking for the correct route. Consequently, by taking systematically the same route, the routinized person could spare themselves the flexibility necessary for simultaneously searching for the correct route and driving correctly. While flexibility is more necessary to undertake new activities, this would not be the case for speed of processing or working memory, in which the levels would remain the same whether the activity is new or not.

Although the present results suggest that excessive routinization modified flexibility, an alternative explanation is possible. Older adults with low flexibility resources could seek behavioral routines in order to adaptively lower the task demands. Bidirectional causality might also provide an explanation of the results as, in return, high routinization could further reduce flexibility resources. Given that the design of the present study did not make it possible to determine this causality, longitudinal studies would be relevant for obtaining more precise information in future research (Hess, 2001). Interestingly, the interventional study reported by Tranter and Koutstaal (2008), involving a large increase in engagement in novel stimulating activities during a period of 10-12 weeks, suggested that the variety and novelty of an environment is beneficial to cognitive performances. Additionally, studies with animals showed that exposure to an enriched environment produced preservation of cognitive functioning and various changes in neurotransmitters and neurogenesis (Mora, Segovia, \& del Arco, 2007). Animal studies also avoid many of the confounding variables involved in human studies like motivation or differences in diet. These studies reinforce the hypothesis that daily life behaviors influence cognition and that the effect of cognition on behaviors cannot be explained only by the fact that poor flexibility leads to poor variety in daily life behaviors. Contrary to Reich and Zautra (1991), Bouisson and colleagues (Bergua et al., 2006; Bouisson, 2002) did not consider the personality aspect of routinization. They took routines to be an adaptive strategy to cope with the stress associated with novel situations that could become a routinization of behavioral activities representing a maladaptive process. Furthermore, Zisberg et al. (2009) concluded that "routinization may be more of an adaptive response than a fixed response pattern rooted in personality" (p. 26). They showed that disliking the disruption component is 
negatively correlated with scales measuring autonomy in activities of daily life. This link with execution of daily life activities such as taking medication or handling finances was first mentioned by Bergua et al. (2006), and showed the necessity to take into account the possible impact of routinization on adaptation to daily life. Previous studies have shown that execution of daily life activities is associated with neuropsychological tests (Barberger-Gateau, Fabrigoule, Rouch, Letenneur, \& Dartigues, 1999; Mell-McGinty, Podell, Franzen, Williams, \& Baird, 2002)). Specifically, the TMT part B predicted functional abilities in the execution of daily life activities (Bell-McGinty et al., 2002), thus confirming the importance of flexibility. These observations suggest that flexibility, or executive functions, could be an important part of the relationship between routinization and daily life activities. Executive functions broadly encompass cognitive skills and processes necessary to execute complex behaviors (Daniels, Toth, Jacoby, Bialystok, \& Craik, 2006). Further studies will provide further insight into the links between routinization and supplementary measures of cognitive flexibility or other executive functions like inhibition and planning.

The results of the current research should be interpreted with caution given the relative low number of both young and older participants. Indeed, a small sample size can lead to inconsistent findings, with a lack of sufficient statistical power increasing the risk of not detecting all of the effects (Shen, Kiger, Davies, Rasch, Simon, \& Ones, 2011). In the present study, we observed that in older adults the higher routinized participants had a smaller span size than the lower routinized participants, although the difference was not reliable. A larger sample size might have shown a significant difference. Another limitation of the study is the relative homogeneity of our population that was composed of highly educated and active young and older participants. Consequently, further studies using a larger sample size as well as a more various population are needed to confirm our findings and to generalize the results to other populations. Finally, as mentioned previously, we examined the links between routinization and cognitive resources using a cross-sectional design. Thus, future study examining the longitudinal association of routinization with cognitive resources should be conducted to confirm our cross-sectional findings.

In conclusion, the present study demonstrates links between routinization in daily life activities and the reduction in cognitive flexibility, emphasizing the need to better understand the individual characteristics that influence the balance between cognitive capacities and daily life adaptation. This research is in the continuity of previous researches showing the importance of variety in daily life activities in later life. In light of recent work emphasizing the need to develop cognitive training close to daily life characteristics in order to enhance the cognitive abilities of elderly adults (Green \& Bavelier, 2008), it seems necessary to investigate variability in daily life. A tempting application of our study would be to try to alleviate the established habits of routinized old adults. However, previous attempts to reduce habits like substance abuse or stereotype formation 
generated negative affects and ironic effects with an increase in the emergence of habits (e.g., Wood \& Neal, 2007). Moreover, given that the desire for simple structures could have positive effects on mental health, Ciarrochi et al. (2005) specified that the object of an intervention is not an increase in openness per se. They emphasized that the focus should be the transition between the desire for structure and the demand for structure, only the latter being associated negatively with mental health. Therefore, the results of the present study are in line with researches showing a benefit of varied activities on cognitive aging and highlight the necessity to consider factors influencing engagement in non-routine activities. Thus, it seems important to act upstream to contain excessive routinization and allow elderly adults to enjoy a complex daily life environment favorable for maintaining cognitive functioning.

\section{REFERENCES}

Aarts, H., \& Dijksterhuis, A. (2000). Habits as knowledge structures: Automaticity in goal-directed behavior. Journal of Personality and Social Psychology, 78, 53-63.

Amieva, H., Lafont, S., Auriacombe, S., Rainville, C., Orgogozo, J., Dartigues, J., et al. (1998). Analysis of error types in the Trail Making Test evidences inhibitory deficit in dementia of the Alzheimer type. Journal of Clinical and Experimental Neuropsychology, 20, 280-285.

Baddeley, A. (1986). Working memory. New York: Clarendon Press/Oxford University Press.

Barberger-Gateau, P., Fabrigoule, C., Rouch, I., Letenneur, L., \& Dartigues, J. (1999). Neuropsychological correlates of self-reported performance in instrumental activities of daily living and prediction of dementia. The Journal of Gerontology: Psychological Sciences, 54B, 293-303.

Bell-McGinty, S., Podell, K., Franzen, M., Williams, M. J., \& Baird, A. D. (2002). Standard measures of executive function in predicting instrumental activities of daily living in older adults. International Journal of Geriatric Psychiatry, 17, 828-834.

Bergua, V., Fabrigoule, C., Barberger-Gateau, P., Dartigues, J., Swendsen, J., \& Bouisson, J. (2006). Preferences for routines in older people: Associations with cognitive and psychological vulnerability. International Journal of Geriatric Psychiatry, 21, 990-998.

Betsch, T., Fiedler, K., \& Brinkmann, J. (1998). Behavioral routines in decision making: The effects of novelty in task presentation and time pressure on routine maintenance and deviation. European Journal of Social Psychology, 28, 861-878.

Bouisson, J. (2002). Routinization preferences, anxiety, and depression in an elderly French sample. Journal of Aging Studies, 16, 295-302.

Bouisson, J., \& Swendsen, J. (2003). Routinization and emotional well-being: An experience sampling investigation in an elderly French sample. The Journal of Gerontology: Psychological Sciences, 58B, 280-282.

Chown, S. M. (1959). Rigidity: A flexible concept. Psychological Bulletin, 56, 195-223.

Ciarrochi, J., Said, T., \& Deane, F. P. (2005). When simplifying life is not so bad: The link between rigidity, stressful life events, and mental health in an undergraduate population. British Journal of Guidance \& Counselling, 33, 185-197. 
Crowe, S. F. (1998). The differential contribution of mental tracking, cognitive flexibility, visual search, and motor speed to performance on Parts A and B of the Trail Making Test. Journal of Clinical Psychology, 54, 585-591.

Daffner, K. R., Chong, H., Riis, J., Wolk, D. A., Holcomb, P. J., Budson, A. E., et al. (2007). Cognitive status impacts age-related changes in attention to novel and target events in normal adults. Neuropsychology, 21, 291-300.

Daffner, K. R., Ryan, K. K., Williams, D. M., Budson, A. E., Rentz, D. M., Wolk, D. A., et al. (2006). Increased responsiveness to novelty is associated with successful cognitive aging. Journal of Cognitive Neuroscience, 18, 1759-1773.

Daniels, K., Toth, J., Jacoby, L., Bialystok, E., \& Craik, F. I. M. (2006). The aging of executive functions. In Lifespan cognition: Mechanisms of change (pp. 96-111). New York: Oxford University Press.

Deltour, J. J. (1998). Echelle de vocabulaire Mill-Hill de J.-C. Raven, adaptation française. Paris: EAP.

Emery, L., Hale, S., \& Myerson, J. (2008). Age differences in proactive interference, working memory, and abstract reasoning. Psychology and Aging, 23, 634-645.

Fabrigoule, C., Letenneur, L., Dartigues, J., \& Zarrouk, M. (1995). Social and leisure activities and risk of dementia: A prospective longitudinal study. Journal of the American Geriatrics Society, 43, 485-490.

Finkel, D., Reynolds, C. A., McArdle, J. J., \& Pedersen, N. L. (2007). Age changes in processing speed as a leading indicator of cognitive aging. Psychology and Aging, 22, 558-568.

Folstein, M. F., Folstein, S. E., \& McHugh, P. R. (1975). Mini-mental state: A practical method for grading the cognitive state of patients for the clinician. Journal of Psychiatric Research, 12, 189-198.

Green, C. S., \& Bavelier, D. (2008). Exercising your brain: A review of human brain plasticity and training-induced learning. Psychology and Aging, 23, 692-701.

Hertzog, C., Dixon, R. A., Hultsch, D. F., \& MacDonald, S. W. S. (2003). Latent chance models of adult cognition: Are changes in processing speed and working memory associated with changes in episodic memory? Psychology and Aging, 18, 755-769.

Hess, T. M. (2001). Ageing-related influences on personal need for structure. International Journal of Behavioral Development, 25, 482-490.

Hommel, B., Li, K. Z. H., \& Li, S.-C. (2004). Visual search across the life span. Developmental Psychology, 40, 545-558.

Hultsch, D. F., Hertzog, C., Small, B. J., \& Dixon, R. A. (1999). Use it or lose it: Engaged lifestyle as a buffer of cognitive decline in aging? Psychology and Aging, 14, 245-263.

Kliegel, M., Zimprich, D., \& Rott, C. (2004). Life-long intellectual activities mediate the predictive effect of early education on cognitive impairment in centenarians: A retrospective study. Aging \& Mental Health, 8, 430-437.

Kramer, A. F., \& Madden, D. J. (2008). Attention. In F. I. M. Craik \& T. A. Salthouse (Eds.), The handbook of aging and cognition (3rd ed., pp. 189-249). New York: Psychology Press.

Kray, J., Li, K. Z. H., \& Lindenberger, U. (2002). Age-related changes in task-switching components: The role of task uncertainty. Brain and Cognition, 49, 363-381.

Lemke, U., \& Zimprich, D. (2005). Longitudinal changes in memory performance and processing speed in old age. Aging, Neuropsychology, and Cognition, 12, 57-77. 
Levitt, T., Fugelsang, J., \& Crossley, M. (2006). Processing speed, attentional capacity, and age-related memory change. Experimental Aging Research, 32, 263-295.

Mora, F., Segovia, G., \& del Arco, A. (2007). Aging, plasticity and environmental enrichment. Structural changes and neurotransmitter dynamics in several areas of the brain. Brain Research Reviews, 55, 77-88.

Neuberg, S. L., \& Newsom, J. T. (1993). Personal need for structure: Individual differences in the desire for simple structure. Journal of Personality and Social Psychology, 65, 113-131.

Newson, R. S., \& Kemps, E. B. (2005). General lifestyle activities as a predictor of current cognition change in older adults: A cross-sectional and longitudinal examination. The Journal of Gerontology: Psychological Sciences, 60B, 113-120.

Park, D. C., Smith, A. D., Lautenschlager, G., Earles, J. L., Frieske, D., Zwahr, M., et al. (1996). Mediators of long-term memory performance across the life span. Psychology and Aging, 11, 621-637.

Reich, J. W., \& Zautra, A. J. (1991). Analysing the trait of routinization in older adults. International Journal of Aging and Human Development, 32, 161-180.

Reitan, R. M. (1958). Validity of the Trail Making Test as an indicator of organic brain damage. Perceptual and Motor Skills, 8, 271-276.

Rokeach, M. (1960). The open and closed mind: Investigations into the nature of belief systems and personality systems. Oxford, England: Basic Books.

Salthouse, T. A. (1991). Mediation of adult age differences in cognition by reductions in working memory and speed of processing. Psychological Science, 2, 179-183.

Salthouse, T. A. (1994a). The aging of working memory. Neuropsychology, 8, 535-543.

Salthouse, T. A. (1994b). The nature of the influence of speed on adult age differences in cognition. Developmental Psychology, 30, 240-259.

Salthouse, T. A. (1996). The processing-speed theory of adult age differences in cognition. Psychological Review, 103, 403-428.

Salthouse, T. A., Kausler, D. H., \& Saults, J. S. (1988). Utilization of path-analytic procedures to investigate the role of processing resources in cognitive aging. Psychology and Aging, 3, 158-166.

Schaie, K. W. (1984). Midlife influences upon intellectual functioning in old age. International Journal of Behavioral Development, 7, 463-478.

Schooler, C., \& Mulatu, M. S. (2001). The reciprocal effects of leisure time activities and intellectual functioning in older people: A longitudinal analysis. Psychology and Aging, 16, 466-482.

Schultz, P. W., \& Searleman, A. (2002). Rigidity of thought and behavior: 100 years of research. Genetic, Social, and General Psychology Monographs, 128, 165-207.

Shen, W., Kiger, T. B., Davies, S. E., Rasch, R. L., Simon, K. M., \& Ones, D. S. (2011). Samples in applied psychology: Over a decade of research in review. Journal of Applied Psychology, 96, 1055-1064.

Stine-Morrow, E. A. L. (2007). The dumbledore hypothesis of cognitive aging. Current Directions in Psychological Science, 16, 295-299.

Thompson, M. M., Naccarato, M. E., Parker, K. C. H., Moskowitz, G. B., \& Moskowitz, G. B. (2001). The personal need for structure and personal fear of invalidity measures: Historical perspectives, current applications, and future directions. In G. B. Moskowitz (Ed.), Cognitive social psychology: The Princeton Symposium on the Legacy and Future of Social Cognition (pp. 19-39). Mahwah, NJ: Lawrence Erlbaum Associates. 
Tournier, I., \& Postal, V. (2010). Effects of depressive symptoms and routinization on metamemory during adulthood. Archives of Gerontology and Geriatrics. Advance online publication. 10.1016/j.archger.2010.01.019.

Tranter, L. J., \& Koutstaal, W. (2008). Age and flexible thinking: An experimental demonstration of the beneficial effects of increased cognitively stimulating activity on fluid intelligence in healthy older adults. Aging, Neuropsychology, and Cognition, $15,184-207$.

Tun, P. A., O'Kane, G., \& Wingfield, A. (2002). Distraction by competing speech in young and older adult listeners. Psychology and Aging, 17, 453-467.

Turner, M. L., \& Engle, R. W. (1989). Is working memory capacity task dependent? Journal of Memory and Language, 28, 127-154.

Verhaeghen, P., \& De Meersman, L. (1998). Aging and the Stroop effect: A meta-analysis. Psychology and Aging, 13, 120-126.

Verplanken, B. (2006). Beyond frequency: Habit as mental construct. British Journal of Social Psychology, 45, 639-656.

Vollhardt, L. T. (1990). Rigidity: A comparison by age and gender. Social Behavior and Personality, 18, 17-26.

Wade, D. T., \& Vergis, E. (1999). The short Orientation-Memory-Concentration test: A study of its reliability and validity. Clinical Rehabilitation, 13, 164-170.

Wood, W., \& Neal, D. T. (2007). A new look at habits and the habit-goal interface. Psychological Review, 114, 843-863.

Wood, W., Quinn, J. M., \& Kashy, D. A. (2002). Habits in everyday life: Thought, emotion, and action. Journal of Personality and Social Psychology, 83, 1281-1297.

Zacks, R. T., Hasher, L., Li, K. Z. H. (2000). Human memory. In F. I. M. Craik \& T. A. Salthouse (Eds.), The handbook of aging and cognition (pp. 293-357). Mahwah, NJ: Lawrence Erlbaum Associates.

Zisberg, A., Zysberg, L., Young, H. M., \& Schepp, K. G. (2009). Trait routinization, functional and cognitive status in older adults. The International Journal of Aging and Human Development, 69, 17-29.

\section{Direct reprint requests to:}

Isabelle Tournier

Institut Français des Sciences et Technologies des Transports

de l'Aménagement et des Réseaux

Laboratoire de Psychologie de la Conduite

25 allée des Marronniers

F-78000 Versailles Satory

France

e-mail: isabelle.tournier14@gmail.com 